\title{
MODIFICATION OF THE COMPARATIVE VALUATION METHOD FOR VALUATION OF A SET OF REAL ESTATE WITH AN INSUFFICIENTLY LARGE BATTERY OF COMPARABLE PROPERTY
}

\author{
${ }^{a}$ TOMÁŠ KRULICKÝ, ${ }^{\mathrm{b}} \mathrm{MAREK} \mathrm{VOCHOZKA}$ \\ ${ }^{a}$ Institute of Technology and and Business in České Budějovice, \\ School of Expertness and Valuation, Okružní 517/10, 37001 \\ České Budějovice, Czech Republic \\ ${ }^{b}$ Institute of Technology and and Business in České Budějovice, \\ School of Expertness and Valuation, Okružní 517/10, 37001 \\ České Budějovice, Czech Republic \\ email: ${ }^{a}$ krulicky@mail.vstecb.cz, ${ }^{b}$ vochozka@mail.vstecb.cz
} possibility of a selected valuation method which can be used to value real estate in case it is not possible to find a sufficiently large battery of comparable real estate to determine the estimate of the market price. The modification of the selected valuation method consists in the double use of correction coefficients in the creation process of the so-called standardized unit of thought which serves as an intermediary in the valuation of specific real estate. Based on the results achieved by the application, it was concluded that such a modified valuation method can be used to estimate the market price of a set of real estate more quickly and efficiently.

Keywords: comparative valuation method, real estate valuation, standardized unit of thought, correction coefficients

\section{Introduction}

Valuation is involved in many fields across different industries. The assessor presents his opinion on the usual price of the subject of valuation (i.e., the market price) as a third impartial and unaffected person. However, in specific cases of valuation, this can be a very complex process which, in most cases, requires a large battery of input data serving as a basis for determining the correct (reasonable) market price with respect to all facts that are specific to the subject of valuation. The correct and sufficient size of the input data battery is also important in order to be able to substantiate the presented valuation result with the relevant facts on which the valuation result is based.

The assessor is faced with requirements for the valuation of various types of both movable and immovable property or their sets, as well as with the valuation of various types of assets (tangible, intangible and financial). However, it is always necessary for the assessor to approach each subject of valuation individually as this is the only way to approach the task correctly while maintaining the perspective of a third independent rational person.

A very specific area explored in the field of valuation as such is the real estate valuation. Several valuation methods can be used to value real estate. However, they are all demanding on the size of the input data battery as in the case of other valuation items (movables, businesses, etc.). The real estate market seems to be a place where, in terms of valuation, obtaining a sufficiently large battery of input data should be fairly simple. In specific cases, however, the opposite may be true.

The aim of this paper is to provide a valuation of a set of real estate - namely residential units (RU), commercial units (CU) and non-residential units (NU) - if there is lack of input data for the valuation of each of the specific real estate field using a modified methodological process commonly used for real estate valuation. To demonstrate the application of the modified valuation methods, these methodological procedures will be applied to a model real estate.

\section{Literature research}

The assessor's view of the subject of valuation should always remain unbiased and the estimated market price should be supported by relevant background data from a sufficiently large data battery. Subsequently, the assessor should take into consideration all circumstances and influences having any effect on the market price of the assessed object.

According to Bellman et al. (2016), assessors with a university degree in the field of expertness and valuation use more complex thought processes and formulas in the valuation procedures than assessors without such focused education. This ultimately affects the correctness and credibility of their decisions. KucharskaStasiak (2014) sought the reasons and possible causes of different opinions on the market price of the subject of valuation of two or more appraisers. She also adds that legislation containing a description and precise definition of valuation principles should help to unify the resulting market price of the subject of valuation in case multiple assessors value the same object. This should also contribute to the plausibility of the set market price of the subject of the valuation. The expert should also have an overview of price maps of the areas in which he performs expert activities. Index maps can also be used for this purpose. Index maps contain information on the values of real estate in a given area, which have been determined in the previous few years (Hromada, 2013).

Several valuation methods can be used when valuing real estate. According to Gabrielli and French (2020), the assessor should first correctly identify the valuation method that they plan to apply. Subsequently, they must perform the given mathematical calculation without errors. However, all assessors should adhere to International Valuation Standards established by the Valuation Standards Board when determining the market price of a particular item.

In valuation practice, however, new valuation methods are gradually being added, which provides the possibility of more accurate determination of the market price of the subject of valuation. With the help of these new valuation methods, it is possible to reduce the difference between the market price of the subject of valuation determined by the assessor and the final sale price in the purchase/sale relationship. According to Abidoy et al. (2019) who conducted a questionnaire survey among Australian assessors, the assessors rarely accept new valuation methods.

However, many assessors specialize in valuation of specific items. A large part consists of assessors who deal with real estate valuation. In some cases of real estate sales, however, the owners determine the offer price of the real estate themselves without any prior knowledge of the real estate market. In many cases, these are very exorbitant price offers which destabilize the entire real estate market in the area. According to Small et al. (2016), this should be prevented by paying attention to the economic sustainability of the set market price when determining the market price of the subject of valuation. Otherwise, the destabilization of the real estate market would have negative economic and political consequences. However, according to Meszek (2013), the real estate market may present inhomogeneous information about the market prices of specific properties. Therefore, a property owner who wants to sell his property has little chance of setting a reasonable and realizable offer price which would eventually become the final sale price without any further changes. This is caused by the fact that the offer prices on the real estate market are very different from the final sale prices and the laymen thus do not have the opportunity to orientate themselves effectively on this market.

Many authors also dealt with the individual valuation methods that can be used in real estate valuation. Krulický et al. (2020) provided a comparison of a property valuation result regarding the property as a single functional unit with the valuation result taking into account its individual parts as the spatial disposition of the property which was referred to as the model valuation item allowed the seller to choose between the two sales options. 
As the assessed real estate consisted of both residential and commercial premises, a combination of the property and income valuation methods was used for the partial valuation of the real estate. Kutasi and Badics (2016) examined various valuation methods that can be used in real estate valuation, especially in predicting the development of the market prices, including the determinants that influence this development. They dealt mainly with hedonic regression analysis and real estate valuation using artificial neural networks (ANN). Based on the achieved results, they came to the conclusion that ANN of the Multi-Layer Perceptron (MLP) type are most suitable for predicting the development of real estate market prices. Hromada (2016) consider the comparative method of valuing real estate as the most common, and he himself proposes a method of valuation using data mining software. This software containin historical detailed information about realized sales of real estate from the begining of their initial offer. The use of the hedonic valuation model in the field of real estate valuation is a much-discussed topic itself. Evans (2012) examined the accuracy of the hedonic valuation model in the field of real estate valuation. However, its accuracy depends heavily on the fact whether the market price of the property is adjusted accordingly after its application. However, this is very difficult to verify due to the model's nature. According to Abidoy and Chan (2018), the hedonic valuation model is very inaccurate, so they made a comparison of a prediction using this model and the ANN. It was found out that the prediction of the real estate market price is more accurate using the ANN than using the hedonic valuation model. They, therefore, recommend the use of ANN to predict the development of the market value of real estate.

In its application, the hedonic model takes into account aspects that are directly related to the environment and environmental influences that may have an external impact on the creation of the market price of the valued real estate. Kucharska-Stasiak and Olbińska (2018) dealt with the environmental valuation of sustainable buildings. Sustainable properties should bring certain economic benefits to their owners. However, current valuation models are not able to incorporate the sustainability viewpoint into the valuation process.

An independent category of real estate valuation is represented by valuation of new buildings. Ferreira et al. (2016) used a multi-criteria valuation method to determine the market price of a new building. According to them, cognitive mapping and measuring attractiveness by a categorical based evaluation technique can help in using the multicriteria valuation method to reasonably estimate the bid prices of new buildings.

Tajani et al. (2019) note that different institutions (banks, insurance companies, etc.) need to constantly determine the market price of very similar types of real estate. Therefore, they propose the creation of a model property as a universal building which is valued at the usual market price. According to the location and the subsequent application of weights, the usual market price of the model property would be modified to determine the market price of the valued property which differs only slightly from the model property. Gdakowicz and PutekSzelag (2020) used statistical methods to determine the individual weights to determine the market value of real estate. Tajani et al. (2018) have also proposed an automated valuation model for real estate valuation in the past. This valuation model was based on model real estate the value of which is assessed by means of all the usual valuation methods (property, yield and market). Later on, this model property can be used as a comparison parameter to value other properties or their sets.

During the economic crisis, individual markets are destabilized. This also applies to the real estate market. Due to the unfavourable economic situation, the real estate market thus becomes an inefficient and inhomogeneous market. Alexandridis et al. (2019) therefore compared the applicability of linear and nonlinear models based on regression, hedonic models and ANN to predict the development of the market price of real estate in an environment of the unstable and inhomogeneous real estate market. By combining all of the above methods, prediction errors can be eliminated to a minimum. According to Krulický and Horák (2019), real estate can also be seen as an investment opportunity. Baranano et al. (2020) used the Monte Carlo simulation to determine the size of the investment risk in real estate for the individual institutions (especially for banks and insurance companies) and to determine the amount of capital needed as a guarantee. This provides a possibility of incorporating possible losses into the valuation model. Vrbka et al. (2020) also point out, however, that due to incorrect investment in real estate, its value may even decrease.

The current phenomenon on the real estate market consists in different owners of the building and the land on which the building stands. Vrbka et al. (2019) therefore dealt with the determination of the rent for the built-up part of the building plot, the owner of which does not coincide with the owner of the building standing on the incriminated part of the plot. Jilemnicka, Berka and Hromada (2008) were interested in the development of the real estate market in the Czech Republic. Software EVAL, was used for mapping and evaluation of the real estate market development.

\section{Data and methods}

First, thought residential units will be created which will represent a standardized RU without any peculiarities and will subsequently serve as intermediaries for valuing RU in model real estate demonstrating the use of a modified methodology for valuing real estate with a small battery of comparable units. A comparative valuation method with the application of correction coefficients will be used and the unit price of RU will be determined on the basis of the offer prices obtained by a survey of RU offered for sale on Internet real estate portals. To assess the value of a specific RU in the model real estate, correction coefficients will again be applied to the determined unit price of the standardized thought RU to specify and take into account the specific properties of the valued unit in the model real estate. Other CU and NU in the model real estate will be valued using the yield valuation method.

The model property consists of six above-ground floors and two underground floors. The whole property has a total of $12 \mathrm{RU}$, two CU and two NU. The CU in the model real estate represents two commercial stores and the NU represent storage spaces that can be used independently of other units in the model real estate. For a more detailed description, a list of all units together with their spatial disposition and floor surface area is given in Table

Table 1: Units in the model real estate including their spatial disposition and floor surface area

\begin{tabular}{|c|c|c|c|}
\hline ID & Type of Unit & $\begin{array}{c}\text { Spatial } \\
\text { Disposition }\end{array}$ & $\begin{array}{c}\text { Floor Surface } \\
\text { Area }\left[\mathrm{m}^{2}\right]\end{array}$ \\
\hline 1 & BJ 1 & $1+1$ & 38.84 \\
\hline 2 & BJ 2 & $2+1$ & 48.11 \\
\hline 3 & BJ 3 & $3+1$ & 87.22 \\
\hline 4 & BJ 4 & $2+1$ & 76.40 \\
\hline 5 & BJ 5 & $3+1$ & 85.72 \\
\hline 6 & BJ 6 & $2+1$ & 79.81 \\
\hline 7 & BJ 7 & $2+1$ & 84.50 \\
\hline 8 & BJ 8 & $3+1$ & 82.50 \\
\hline 9 & BJ 9 & 3+kitchenette & 83.74 \\
\hline 10 & BJ 10 & $2+1$ & 80.21 \\
\hline 11 & BJ 11 & $1+1$ & 49.97 \\
\hline 12 & BJ 12 & 1+kitchenette & 31.21 \\
\hline 13 & CU 1 & & 63.85 \\
\hline 14 & CU 2 & & 80.27 \\
\hline
\end{tabular}




\begin{tabular}{|l|l|l|l|}
15 & NU 1 & & 65.31 \\
\hline 16 & NU 2 & & 68.73 \\
\hline
\end{tabular}

Source: Authors.

In the first step, the standardized thought RU will be created. The RU in the model property will be divided into two groups according to the size of the floor area. Group No. 1 will include RU with $50 \mathrm{~m}^{2}$ of floor surface area, i.e., RU No. 1, 2, 11 and 12. Group No. 2 will include RU with more than $50 \mathrm{~m}^{2}$ of floor surface area, i.e., RU No. 3-10. Subsequently, two batteries of similar RU will be searched on Internet real estate portals for both created RU groups. When searching for a suitable battery of comparable data, the floor surface area of the offered RU will be primarily taken into account, i.e., up to $\pm 50 \mathrm{~m}^{2}$ and over $50 \mathrm{~m}^{2}$. Based on the floor surface area and the offer prices of RU, the unit offer price (UOP) for each of the identified RU for sale from both groups will be determined. Subsequently, the correction factors $\mathrm{K}_{1}-\mathrm{K}_{5}$ will be applied to the individual UOP of the traced RU in order to create an adjusted unit price (AUP) of the standardized thought RU for both groups. The coefficients $\mathrm{K}_{1}$ $\mathrm{K}_{5}$ represent the following correction criteria: $\mathrm{K}_{1}-$ the coefficient of reduction of the price source will be used in all cases, as it is always the offer price of the RU in question; $\mathrm{K}_{2}-$ the locality coefficient will represent the degree of difference from the standardized RU; $\mathrm{K}_{3}$ - technical condition will represent the difference of the technical condition of $\mathrm{RU}$ in comparison with the standardized thought RU; $\mathrm{K}_{4}$ - coefficient of fittings will compare the equipment of RU in the form of ancillary buildings, real estate equipment or specifics of land belonging to buildings and, finally, coefficient $\mathrm{K}_{5}-$ coefficient of time interval taking into account the general developments in real estate prices. After applying these correction coefficients, the AUP of each of the detected RU in both groups will be determined. The subsequent creation of the average of all AUP will determine the unit price (UP) of the standardized thought $\mathrm{RU}$ for each of the RU groups separately.

After determining the UP created for the standardized thought RU in both groups, selected correction coefficients will be applied to these unit prices once more taking into account the differences between the standardized thought RU and the RU which are valued within the model real estate. These will be the correction coefficients $K_{2}-K_{4}$. The correction coefficients $K_{1}$ and $\mathrm{K}_{5}$ will no longer be applied as the UP created for both groups of standardized RU is not an offer price, nor is there any time lag in the development of real estate prices. By applying the correction coefficients $\mathrm{K}_{2}-\mathrm{K}_{4}$, the adjusted unit price of the residential unit (AUP ${ }^{\mathrm{RU}}$ ) will be determined for both groups which are valued within the model real estate. A subsequent multiplication of $\mathrm{AUP}^{\mathrm{RU}}$ by the floor surface area of the RU from both groups will determine the market prices of all RU in the model real estate.

Furthermore, the valuation of $\mathrm{CU}$ and $\mathrm{NU}$ will be performed. As $\mathrm{CU}$ and $\mathrm{NU}$ can generally be expected to have their future revenue potential, these units will be valued using the yield valuation method. However, when using the yield valuation method, from the point of view of a third independent rational person represented by the assessor, it is necessary to follow the highest and best use rule. In valuation practice, this rule is obeyed when determining the amount of potentially collected rent. To determine the potential amount of collected rent from CU and NU in the model real estate, an input data battery containing $\mathrm{CU}$ rental offer prices and an input data battery containing NU rental offer prices will be traced on online real estate portals. Based on the offer prices and the floor surface area in both data batteries, UOP from the rent of CU and NU will be determined. Subsequently, the UOP from both data batteries will be adjusted using the correction coefficients $\mathrm{K}_{1}$ $\mathrm{K}_{3}$. After applying the correction coefficients $\mathrm{K}_{1}-\mathrm{K}_{3}$, the adjusted offer unit prices of individual CU (AUOP ${ }^{\mathrm{CU}}$ ) and $\mathrm{NU}$ $\left(\mathrm{AUOP}^{\mathrm{NU}}\right)$ will be determined. Subsequent creation of averages of all $\mathrm{AUOP}^{\mathrm{CU}}$ and $\mathrm{AUOP}^{\mathrm{NU}}$ will determine the average amount of $\mathrm{AUOP}{ }^{\mathrm{CU}}$ and $\mathrm{AUOP}^{\mathrm{NU}}$.
Furthermore, the amount of potential annual rent from the lease of $\mathrm{CU}$ and $\mathrm{NU}$ in the model real estate will be determined using the Formula No. 1.

$$
\begin{aligned}
& \text { potential annual rent } \\
& =\text { average } A U O P * 12 \text { months } \\
& * \text { floor surface area. }
\end{aligned}
$$

In the next step, the yield value of $\mathrm{CU}$ and $\mathrm{NU}$ will be determined. The calculation of the yield value of $\mathrm{CU}$ and $\mathrm{NU}$ must take into account the possible loss of rent for the owner in the amount of $10 \%$ of the potential annual rent, which represents a certain reserve when changing the tenant of the $\mathrm{CU}$ and $\mathrm{NU}$. Furthermore, it is necessary to take into account the costs of insurance and other expenses associated with the operation of $\mathrm{CU}$ and $\mathrm{NU}$, as the operation of these units is riskier than the operation of RU. These costs will be calculated in the total amount of $30 \%$. Finally, the capitalization rate will be applied to determine the market value of $\mathrm{CU}$ and NU. The capitalization rate for CU is set at $7 \%$ by a decree (Czechia, 2013). In the case of German, where storage facilities are specific, the capitalization rate is set at $6 \%$ by decree (Czechia, 2013). The yield value of $\mathrm{CU}$ and $\mathrm{NU}$ will be determined according to the Formula No. 2

$$
\begin{aligned}
& \text { Yield value } \\
& =\frac{\text { potential annual rent reduced by costs }}{\text { annual capitalization rate }} .
\end{aligned}
$$

Subsequently, the unit price will be determined for the rent of $\mathrm{CU}$ and NU by the share of the total yield value for $\mathrm{CU}$ and $\mathrm{NU}$ and the total floor surface area of both units forming the $\mathrm{CU}$ and $\mathrm{NU}$ in the model real estate.

In the next step, the yield value of each of the CU and NU will be determined by the product of unit price for the rent of $\mathrm{CU}$ and $\mathrm{NU}$ and by the specific floor surface area of the particular $\mathrm{CU}$ and NU.

To determine the total market value of the model property, the sum of the market values of all units in the model property determined by specific valuation methods will be performed.

\section{Results}

To begin with, thought residential units were created which represent the standardized RU for both groups of RU created for valuation within the model real estate. A total of $12 \mathrm{RU}$ offers were found on internet real estate portals which corresponded in their parameters to the floor surface area of Group No. 1. The offered residential units are listed in Table 2.

Table 2: Residential units offered on internet real estate portals with a determined unit price (Group No. 1)

\begin{tabular}{|c|c|c|c|}
\hline ID & Price [CZK] & $\begin{array}{c}\text { Floor Surface } \\
{\text { Area }\left[\mathbf{m}^{2} \text { ] }\right.}\end{array}$ & $\begin{array}{c}\text { Unit Price } \\
{\left[\mathbf{C Z K} / \mathbf{m}^{2}\right]}\end{array}$ \\
\hline 1 & $2,200,000$ & 42 & 52,381 \\
\hline 2 & $2,249,000$ & 42 & 53,548 \\
\hline 3 & $1,896,800$ & 36 & 52,689 \\
\hline 4 & $2,492,600$ & 47 & 53,034 \\
\hline 5 & $2,190,000$ & 48 & 45,625 \\
\hline 6 & $2,024,000$ & 44 & 46,000 \\
\hline 7 & $1,950,000$ & 41 & 47,561 \\
\hline 8 & $2,550,000$ & 51 & 50,000 \\
\hline 9 & $2,190,000$ & 48 & 45,625 \\
\hline 10 & $2,585,000$ & 51 & 50,686 \\
\hline 11 & $2,470,000$ & 51 & 48,431 \\
\hline 12 & $2,390,000$ & 52 & 45,962 \\
\hline
\end{tabular}

Source: Authors. 
According to Table 2, it is evident that the unit offer price for residential units with the floor surface area up to $\pm 50 \mathrm{~m}^{2}$ ranged from $53,548 \mathrm{CZK} / \mathrm{m}^{2}$ to $45,625 \mathrm{CZK} / \mathrm{m}^{2}$.

Subsequently, a total of 8 RU offers were again found on internet real estate portals which corresponded in their parameters to the floor surface area of RU in Group No. 2. The offered residential units are listed in Table 3.

Table 3: Residential units offered on internet real estate portals with a determined unit price (Group No. 2)

\begin{tabular}{|c|c|c|c|}
\hline ID & Price [CZK] & $\begin{array}{c}\text { Floor Surface } \\
\text { Area }\left[\mathbf{m}^{\mathbf{}}\right]\end{array}$ & $\begin{array}{c}\text { Unit Price } \\
{\left[\mathbf{C Z K} / \mathbf{m}^{2}\right]}\end{array}$ \\
\hline 1 & $2,785,000$ & 79 & 35,253 \\
\hline 2 & $1,647,000$ & 70 & 23,529 \\
\hline 3 & $3,750,000$ & 82 & 45,732 \\
\hline 4 & $3,399,000$ & 88 & 38,625 \\
\hline 5 & $3,999,000$ & 84 & 47,607 \\
\hline 6 & $3,580,000$ & 74 & 48,378 \\
\hline 7 & $3,590,000$ & 75 & 47,867 \\
\hline 8 & $3,690,000$ & 79 & 46,709 \\
\hline
\end{tabular}

Source: Authors.

Table 3 shows that the unit offer price of residential units with floor surface areas large than $50 \mathrm{~m}^{2}$ ranged from $23,529 \mathrm{CZK} / \mathrm{m}^{2}$ to $48,378 \mathrm{CZK} / \mathrm{m}^{2}$.

In the next step, the correction coefficients K1-K5 were applied to the determined UOP in both groups of RU. Subsequently, the created adjusted offer prices were averaged and thus, unit prices of the standardized thought RU were created for both groups. The results of the application of correction coefficients and the resulting unit prices of the standardized thought residential units are shown in Tables 4 and 5.

Table 4: Results of the application of correction coefficients $\mathrm{K}_{1}$ $\mathrm{K}_{5}$ along with the determination of the average adjusted unit price of the standardized thought residential unit for Group No. 1

\begin{tabular}{|c|c|c|c|c|c|c|c|}
\hline $\mathbf{I D}$ & $\begin{array}{c}\mathbf{U P} \\
{\left[\mathbf{C Z K} / \mathbf{m}^{2}\right]}\end{array}$ & $\mathbf{K}_{\mathbf{1}}$ & $\mathbf{K}_{\mathbf{2}}$ & $\mathbf{K}_{\mathbf{3}}$ & $\mathbf{K}_{\mathbf{4}}$ & $\mathbf{K}_{\mathbf{5}}$ & $\begin{array}{c}\mathbf{A O P} \\
{\left[\mathbf{C Z K} / \mathbf{m}^{2}\right]}\end{array}$ \\
\hline 1 & 52,381 & 0.90 & 1.05 & 0.95 & 1.00 & 1.00 & 47,025 \\
\hline 2 & 53,548 & 0.90 & 1.00 & 0.95 & 1.00 & 1.00 & 45,783 \\
\hline 3 & 52,689 & 0.90 & 1.00 & 1.00 & 1.00 & 1.05 & 49,791 \\
\hline 4 & 53,034 & 0.90 & 1.00 & 0.92 & 1.03 & 1.07 & 48,396 \\
\hline 5 & 45,625 & 0.90 & 1.00 & 1.00 & 1.03 & 1.07 & 45,255 \\
\hline 6 & 46,000 & 0.90 & 1.07 & 1.00 & 1.00 & 1.00 & 44,298 \\
\hline 7 & 47,561 & 0.90 & 1.00 & 1.05 & 1.00 & 1.00 & 44,945 \\
\hline 8 & 50,000 & 0.90 & 1.05 & 1.00 & 1.05 & 0.95 & 47,132 \\
\hline 9 & 45,625 & 0.90 & 1.05 & 1.00 & 1.03 & 1.00 & 44,409 \\
\hline 10 & 50,686 & 0.90 & 1.05 & 1.00 & 1.05 & 0.95 & 47,779 \\
\hline 11 & 48,431 & 0.90 & 1.00 & 1.03 & 1.05 & 1.05 & 49,498 \\
\hline 12 & 45,962 & 0.90 & 1.05 & 0.93 & 1.05 & 1.07 & 45,382 \\
\hline Mean & \multicolumn{7}{|l}{} \\
\hline
\end{tabular}

Source: Authors.

According to Table 4, the average adjusted unit price of the standardized thought residential unit for Group No. 1 was set at $46,641 \mathrm{CZK} / \mathrm{m} 2$.
Table 5: Results of the application of correction coefficients $\mathrm{K}_{1}$ $\mathrm{K}_{5}$ along with the determination of the average adjusted unit price of the standardized thought residential unit for Group No. 2

\begin{tabular}{|c|c|c|c|c|c|c|c|}
\hline ID & \begin{tabular}{c|c}
$\mathbf{U P}$ \\
{$\left[\mathrm{CZK} / \mathrm{m}^{2}\right]$}
\end{tabular} & $\mathbf{K}_{\mathbf{1}}$ & $\mathbf{K}_{2}$ & $\mathbf{K}_{3}$ & $\mathbf{K}_{4}$ & $\mathbf{K}_{5}$ & $\begin{array}{c}\text { AUP } \\
{\left[\mathrm{CZK} / \mathbf{m}^{2}\right]}\end{array}$ \\
\hline 1 & 35,253 & 0.90 & 1.07 & 1.07 & 1.00 & 1.05 & 38,141 \\
\hline 2 & 23,529 & 0.90 & 1.15 & 1.10 & 0.95 & 1.07 & 37,285 \\
\hline 3 & 45,732 & 0.90 & 1.05 & 0.90 & 1.00 & 1.05 & 38,571 \\
\hline 4 & 38,625 & 0.90 & 1.05 & 1.05 & 1.05 & 1.07 & 43,059 \\
\hline 5 & 47,607 & 0.90 & 1.05 & 0.95 & 1.00 & 1.00 & 42,739 \\
\hline 6 & 48,378 & 0.90 & 1.05 & 1.00 & 1.00 & 1.00 & 45,718 \\
\hline 7 & 47,867 & 0.90 & 1.05 & 1.00 & 1.00 & 1.00 & 45,234 \\
\hline 8 & 46,709 & 0.90 & 1.05 & 0.95 & 1.00 & 1.00 & 41,933 \\
\hline & 41,585 \\
\hline
\end{tabular}

Source: Authors.

According to Table 5, the average adjusted unit price of the standardized thought RU in Group No. 2 was set at 41,585 $\mathrm{CZK} / \mathrm{m}^{2}$.

Subsequently, the correction coefficients $\mathrm{K}_{2}-\mathrm{K}_{4}$ were applied to the average adjusted unit price of the standardized thought RU according to the specific specifics of the residential units from Group No. 1 in the model real estate. Table 6 shows the applied correction coefficients for the average AUP of the standardized thought RU according to the specific specifics of RU which belong to Group No. 1 in the model real estate.

Table 6: Determining the adjusted unit price of residential units $\left(\mathrm{AUP}^{\mathrm{RU}}\right.$ ) for Group No. 1

\begin{tabular}{|c|c|c|c|c|c|}
\hline ID & $\begin{array}{c}\mathbf{A U P} \\
{\left[\mathbf{C Z K} / \mathbf{m}^{2}\right]}\end{array}$ & $\mathbf{K}_{\mathbf{2}}$ & $\mathbf{K}_{\mathbf{3}}$ & $\mathbf{K}_{\mathbf{4}}$ & $\begin{array}{c}\mathbf{A U P}^{\mathrm{RU}} \\
{\left[\mathbf{C Z Z} / \mathbf{m}^{2}\right]}\end{array}$ \\
\hline 1 & 46,641 & 1.00 & 0.90 & 0.90 & 37,779 \\
\hline 2 & 46,641 & 0.95 & 0.90 & 0.95 & 37,884 \\
\hline 11 & 46,641 & 0.95 & 0.75 & 1.00 & 33,232 \\
\hline 12 & 46,641 & 1.05 & 1.00 & 1.00 & 48,973 \\
\hline
\end{tabular}

Source: Authors.

Based on the floor surface area of the individual units, the market prices of the particular units were subsequently determined. Moreover, the sum of all market values of RU in Group No. 1 was determined. Table 7 shows the determined market prices of RU from Group No. 1 on the basis of AUP ${ }^{\mathrm{RU}}$.

Table 7: Market prices of residential units from Group No. 1 on Table 7: Market prices
the basis of AUP $^{\mathrm{RU}}$

\begin{tabular}{|c|c|c|c|}
\hline ID & $\begin{array}{c}\text { Floor Surface Area } \\
{\left[\mathrm{m}^{2}\right]}\end{array}$ & $\begin{array}{c}\mathbf{A U P}^{\mathrm{RU}} \\
{\left[\mathrm{CZK} / \mathrm{m}^{2}\right]}\end{array}$ & Final Price [CZK] \\
\hline 1 & 38,84 & 37,779 & $1,467,000$ \\
\hline 2 & 48,11 & 37,884 & $1,823,000$ \\
\hline 11 & 49,97 & 33,232 & $1,661,000$ \\
\hline 12 & 31,21 & 48,973 & $1,528,000$ \\
\hline \multicolumn{3}{|c|}{ Total } & $6,479,000$ \\
\hline
\end{tabular}

Source: Authors.

Based on the floor surface areas of the residential units and the $\mathrm{AUP}^{\mathrm{RU}}$, the total market price of the residential units in Group No.1 was set at 6,479,000 CZK.

In the next step, the correction coefficients $\mathrm{K}_{2}-\mathrm{K}_{4}$ were applied to the AUP of the standardized thought residential units according to the specifics of RU from Group No. 2 in the model real estate. Table 8 shows the applied correction coefficients for the average adjusted unit price of the standardized thought unit 
according to the specifics of RU from Group No. 2 in the model real estate

Table 8: Determining the adjusted unit price of residential units $\left(\mathrm{AUP}^{\mathrm{RU}}\right.$ ) for Group No. 2

\begin{tabular}{|c|c|c|c|c|c|}
\hline ID & $\begin{array}{c}\text { AUP } \\
{\left[\mathbf{C Z K} / \mathbf{m}^{2}\right]}\end{array}$ & $\mathbf{K}_{\mathbf{2}}$ & $\mathbf{K}_{\mathbf{3}}$ & $\mathbf{K}_{\mathbf{4}}$ & $\begin{array}{c}\mathbf{A U P}^{\mathbf{R U}} \\
{\left[\mathbf{C Z K} / \mathbf{m}^{\mathbf{2}}\right]}\end{array}$ \\
\hline 3 & 41,585 & 1.10 & 1.00 & 1.00 & 45,743 \\
\hline 4 & 41,585 & 1.00 & 1.00 & 1.00 & 41,585 \\
\hline 5 & 41,585 & 0.95 & 1.00 & 1.00 & 39,506 \\
\hline 6 & 41,585 & 0.90 & 1.00 & 1.00 & 37,426 \\
\hline 7 & 41,585 & 0.95 & 1.00 & 1.00 & 39,506 \\
\hline 8 & 41,585 & 1.00 & 1.00 & 1.00 & 41,585 \\
\hline 9 & 41,585 & 1.12 & 1.00 & 1.00 & 46,575 \\
\hline 10 & 41,585 & 1.05 & 1.00 & 1.00 & 43,664 \\
\hline
\end{tabular}

Source: Authors.

Based on the floor surface area of the individual units, the market prices of the particular units were subsequently determined. Moreover, the sum of all market values of RU in Group No. 2 was determined. Table 9 shows the determined market prices of RU from Group No. 2 on the basis of $\mathrm{AUP}^{\mathrm{RU}}$

Table 9: Market prices of residential units from Group No. 2 on the basis of AUP ${ }^{\mathrm{RU}}$

\begin{tabular}{|c|c|c|c|}
\hline ID & $\begin{array}{c}\text { Floor Surface Area } \\
{\left[\mathbf{m}^{\mathbf{2}} \mathbf{]}\right.}\end{array}$ & $\begin{array}{c}\mathbf{A U P}^{\mathrm{RU}} \\
{\left[\mathbf{C Z K} / \mathbf{m}^{\mathbf{2}}\right]}\end{array}$ & Final Price $[\mathbf{C Z K}]$ \\
\hline 3 & 87.22 & 45,743 & $3,990,000$ \\
\hline 4 & 76.40 & 41,585 & $3,177,000$ \\
\hline 5 & 85.72 & 39,506 & $3,386,000$ \\
\hline 6 & 79.81 & 37,426 & $2,987,000$ \\
\hline 7 & 84.50 & 39,506 & $3,338,000$ \\
\hline 8 & 82.50 & 41,585 & $3,431,000$ \\
\hline 9 & 83.74 & 46,575 & $3,900,000$ \\
\hline 10 & 80.21 & 43,664 & $3,502,000$ \\
\hline \multicolumn{4}{|l}{ Total }
\end{tabular}

Source: Authors.

Based on the floor surface areas of the residential units and the $\mathrm{AUP}^{\mathrm{RU}}$, the total market price of the residential units in Group No. 2 was set at 27,711,000 CZK.

Subsequently, CU and NU were valued. In the case of CU, it was necessary to start by finding a sufficiently large battery of input data to determine the average potential collected rent. A total of 10 rental offers for commercial units were found on internet real estate portals. The monthly rent, including the floor surface area and the determination of the unit offer price, is given in Table 10.

Table 10: Commercial units offered for rent

\begin{tabular}{|c|c|c|c|}
\hline ID & $\begin{array}{c}\text { Offer Price } \\
{[\mathbf{C Z K}]}\end{array}$ & $\begin{array}{c}\text { Floor Surface Area } \\
\mathbf{[ m}^{\mathbf{2}} \mathbf{]}\end{array}$ & $\begin{array}{c}\text { Unit Offer } \\
\text { Price } \\
{\left[\mathbf{C Z K} / \mathbf{m}^{\mathbf{2}}\right]}\end{array}$ \\
\hline $\mathbf{1}$ & 58,000 & 116 & 500 \\
\hline $\mathbf{2}$ & 32,500 & 128 & 254 \\
\hline $\mathbf{3}$ & 18,000 & 48 & 375 \\
\hline $\mathbf{4}$ & 15,000 & 51 & 294 \\
\hline $\mathbf{5}$ & 22,000 & 87 & 253 \\
\hline $\mathbf{6}$ & 14,000 & 61 & 230 \\
\hline $\mathbf{7}$ & 19,360 & 46 & 421 \\
\hline $\mathbf{8}$ & 37,000 & 145 & 255 \\
\hline $\mathbf{9}$ & 59,000 & 144 & 410 \\
\hline $\mathbf{1 0}$ & 37,500 & 129 & 291 \\
\hline
\end{tabular}

Source: Authors.
According to Table 10, it is evident that the UOP in the offers of commercial units for rent ranged from $230 \mathrm{CZK} / \mathrm{m}^{2}$ and 500 $\mathrm{CZK} / \mathrm{m}^{2}$.

Subsequently, the correction coefficients $\mathrm{K}_{1}-\mathrm{K}_{3}$ were applied to the unit offer price of the found CU rental offers according to the specifics of the CU in the model real estate. Table 11 shows the application of the correction coefficients on the unit offer price of the commercial units and documents the establishment of the adjusted unit offer prices of CU (AUOP ${ }^{\mathrm{CU}}$ ).

Table 11: Determining the AUOP ${ }^{\mathrm{CU}}$

\begin{tabular}{|c|c|c|c|c|c|}
\hline ID & $\begin{array}{c}\mathbf{U O P} \\
{\left[\mathbf{C Z K} / \mathbf{m}^{2}\right]}\end{array}$ & $\mathbf{K}_{\mathbf{1}}$ & $\mathbf{K}_{\mathbf{2}}$ & $\mathbf{K}_{\mathbf{3}}$ & $\begin{array}{c}\mathbf{A U O P} \\
{\left[\mathbf{C Z K} / \mathbf{m}^{2}\right]}\end{array}$ \\
\hline 1 & 500 & 0.90 & 0.90 & 0.85 & 344 \\
\hline 2 & 254 & 1.10 & 1.10 & 1.00 & 307 \\
\hline 3 & 375 & 0.95 & 1.00 & 1.00 & 356 \\
\hline 4 & 294 & 0.95 & 1.05 & 1.05 & 308 \\
\hline 5 & 253 & 0.95 & 1.10 & 1.00 & 264 \\
\hline 6 & 230 & 0.95 & 1.10 & 1.00 & 240 \\
\hline 7 & 421 & 1.00 & 1.00 & 1.00 & 342 \\
\hline 8 & 255 & 0.95 & 0.90 & 1.00 & 218 \\
\hline 9 & 410 & 0.85 & 1.00 & 1.00 & 348 \\
\hline 10 & 291 & 0.95 & 1.00 & 1.00 & 276 \\
\hline Mean & & & & 300 \\
\hline
\end{tabular}

Source: Authors.

According to Table 11 , it is clear that the average $\mathrm{AUOP}^{\mathrm{CU}}$ is $300 \mathrm{CZK} / \mathrm{m}^{2}$. Based on the data given in Table 1 , the total size of the floor surface areas of all commercial units in the model property was set at $144.12 \mathrm{~m}^{2}$.

Subsequently, the amount of the potential annual rent from the CU lease was determined using Formula 3. After substituting into the formula, the following relationship was obtained:

$$
\begin{aligned}
& \text { Potential annual rent } \\
& \quad=300 \mathrm{CZK} / \mathrm{m}^{2} \\
& \quad * 12 \text { months } * 144.12 \mathrm{~m}^{2} \\
& \quad=\mathbf{5 1 8}, \mathbf{8 3 2} \mathrm{CZK} .
\end{aligned}
$$

Subsequently, the yield value of the individual commercial units in the model real estate was determined. First, the potential annual rent was reduced by $10 \%$ representing a certain reserve in case tenants should change (518,832 CZK - 10\% = 466,949 CZK).

All costs associated with the maintenance and insurance of the CU were also taken into account in the amount of 30\% (466,949 CZK - 30\% = 326,864 CZK).

In the next step, the capitalization rate for $\mathrm{CU}$ was applied to determine the yield value of all commercial units in the model real estate by using Formula 4:

$$
\text { Yield value }=\frac{326,864 C Z K}{7 \%}=4,669,486 C Z K
$$

By the subsequent share of the yield value of all commercial units and their total floor surface area, the unit price for the lease of $\mathrm{CU}$ was determined $\left(4,669,486 \mathrm{CZK} / 144.12 \mathrm{~m}^{2}=32,400\right.$ $\left.\mathrm{CZK} / \mathrm{m}^{2}\right)$.

Finally, to determine the yield value of the individual commercial units, the yield values of the individual commercial units in the model real estate were determined on the basis of the floor surface area according to Table 1.

$$
C U 1=32,400 C Z K * 63.85 \mathrm{~m}^{2}
$$

$$
=2,068,740 \mathrm{CZK} \text {. }
$$




$$
\begin{array}{rl}
C U 2=32,400 C Z K * & 80.27 \mathrm{~m}^{2} \\
& =2,600,748 C Z K .
\end{array}
$$

After performing the calculations, CU1 was valued at 2,068,740 CZK and CU2 was valued at 2,600,748 CZK using the yield method in both cases.

In the case of non-residential units, it was also first necessary to find a sufficiently large battery of input data to determine the average potentially collected rent. A total of $6 \mathrm{NU}$ rental offers were found on internet real estate portals. The amount of monthly rent including the floor surface area and the determination of the unit offer price is given in Table 12 .

\begin{tabular}{|c|c|c|c|}
\hline ID & $\begin{array}{l}\text { Offer Price } \\
\text { [CZK] }\end{array}$ & $\begin{array}{l}\text { Floor Surface Area } \\
\qquad\left[\mathrm{m}^{2}\right]\end{array}$ & $\begin{array}{c}\text { Unit Offer } \\
\text { Price } \\
{\left[\mathrm{CZK} / \mathbf{m}^{2}\right]}\end{array}$ \\
\hline 1 & 24,000 & 360 & 66 \\
\hline 2 & 2,000 & 50 & 40 \\
\hline 3 & 17,500 & 300 & 58 \\
\hline 4 & 11,895 & 178 & 67 \\
\hline 5 & 35,000 & 430 & 81 \\
\hline 6 & 17,000 & 214 & 79 \\
\hline
\end{tabular}

Table 12: Rental offers for non-residential units

Source: Authors.

According to Table 12, it is obvious that the UOP ranged from $40 \mathrm{CZK} / \mathrm{m}^{2}$ to $81 \mathrm{CZK} / \mathrm{m}^{2}$ for the found NU rental offers.

Subsequently, the correction coefficients $K_{1}-K_{3}$ were applied to the UOP of the NU rental offers according to the specifics of the particular NU in the model real estate. Table 13 shows the applied correction coefficients for the unit offer price and sets the adjusted unit offer prices $\left(\mathrm{AUOP}^{\mathrm{NU}}\right)$.

Table 13: Determining the AUOP ${ }^{\mathrm{NU}}$

\begin{tabular}{|c|c|c|c|c|c|}
\hline ID & $\begin{array}{c}\mathbf{U O P} \\
{\left[\mathbf{C Z K} / \mathbf{m}^{2}\right]}\end{array}$ & $\mathbf{K}_{\mathbf{1}}$ & $\mathbf{K}_{\mathbf{2}}$ & $\mathbf{K}_{\mathbf{3}}$ & $\begin{array}{c}\mathbf{A U O P} \\
{\left[\mathbf{C Z K} / \mathbf{m}^{\mathbf{2}}\right]}\end{array}$ \\
\hline 1 & 66 & 1.00 & 1.00 & 0.85 & 56 \\
\hline 2 & 40 & 1.02 & 1.00 & 0.95 & 39 \\
\hline 3 & 58 & 1.02 & 0.95 & 0.95 & 53 \\
\hline 4 & 67 & 1.02 & 0.95 & 0.90 & 58 \\
\hline 5 & 81 & 1.02 & 0.95 & 0.80 & 63 \\
\hline 6 & 79 & 1.02 & 0.95 & 0.85 & 65 \\
\hline Mean & & & & 56 \\
\hline
\end{tabular}

Source: Authors.

According to Table 12, it is clear that the average $\mathrm{AUOP}^{\mathrm{NU}}$ totals $56 \mathrm{CZK} / \mathrm{m}^{2}$. Based on the data given in Table 1 , the total size of the floor surface areas of all non-residential units in the model property was set at $134.04 \mathrm{~m}^{2}$.

Subsequently, the amount of potential annual rent from the lease of NU was determined using Formula 1. After substituting into the formula, the following relationship was obtained:

\section{Potential annual rent}

$$
\begin{aligned}
& =56 \mathrm{CZK} / \mathrm{m}^{2} * 12 \text { months } \\
& * 134.04 \mathrm{~m}^{2} \\
& =\mathbf{9 0}, \mathbf{0 7 5} \mathbf{C Z K} .
\end{aligned}
$$

Subsequently, the yield value of individual NU in the model real estate was determined. First, the potential annual rent was reduced by $10 \%$ representing a certain reserve in case tenants should change $(90,075 \mathrm{CZK}-10 \%=81,068 \mathrm{CZK})$.

All costs associated with the maintenance and insurance of the NU were also taken into account in the amount of $30 \%(81,068$ CZK - 30\% = 56,748 CZK).
In the next step, the capitalization rate for NU was applied to determine the yield value of all non-residential units in the model real estate. For this purpose, Formula 2 was used.

$$
\text { Yield value }=\frac{56,748 \mathrm{CZK}}{6 \%}=945,800 \mathrm{CZK} \text {. }
$$

By mean of the subsequent share of the yield value of all nonresidential units and their total size of floor surface areas, the unit price was determined for the lease of NU $(945,800 \mathrm{CZK} /$ $\left.134.04 \mathrm{~m}^{2}=7.056 \mathrm{CZK} / \mathrm{m}^{2}\right)$.

Finally, in order to determine the yield value of the individual non-residential units, the yield values of the individual NU in the model real estate were determined on the basis of the floor surface areas according to Table 1 .

$$
\begin{aligned}
& N U 1=7,056 C Z K * 65.31 m^{2}=460,827 C Z K \\
& N U 2=7,056 C Z K * 68.73 m^{2}=484,959 C Z K
\end{aligned}
$$

After performing the calculations, NU1 was valued at 460,827 CZK and NU2 was valued at 484,959 CZK using the yield method in both cases.

Finally, the sum of all units that formed the model property was valued according to the relevant valuation methods. Table 14 lists all specified values of the individual units and their groups in the model real estate.

Table 14: Market values of the individual constituting units of the model real estate

\begin{tabular}{|l|r|}
\hline \multicolumn{1}{|c|}{$\begin{array}{c}\text { Type of the Constitution } \\
\text { Unit }\end{array}$} & Market Value [CZK] \\
\hline RU (Group No. 1) & $6,479,000$ \\
\hline RU (Group No. 2) & $27,711,000$ \\
\hline CU1 & $2,068,740$ \\
\hline CU2 & $2,600,748$ \\
\hline NU1 & 460,827 \\
\hline NU2 & 484,959 \\
\hline Total & $\mathbf{3 9 , 8 0 5 , 2 7 4}$ \\
\hline
\end{tabular}

Source: Authors.

The sum of the market values of the individual units and their groups which form together the observed model property determined its total market value at 39,805,274 CZK.

\section{Discussion}

In all areas of research and development, various procedures and methods are being modernized over time, the progress of which will always improve the previous methodological procedures in a certain direction. These innovative approaches and methods usually involve the implementation of other complex steps that can be used to improve the final product. In some cases, however, such progress is not required and, ultimately, not effective. In these cases, we can talk about an innovation that will bring a certain universality of the whole process and thus this process can be used in other areas than for which it was originally designed.

In the valuation practice, a typical shortcoming of a large set of valuation methods is the need for the largest possible battery of input background data to determine the most accurate estimate of the market price of the subject of valuation. In some cases, it is not even possible to find adequate input data for the subject of valuation on the basis of which it would be possible to determine the market price of the subject of valuation. For this reason, in valuation practice, it is constantly talked only about estimates of market prices of the valued items. However, the presented methodological procedure enables the valuation of a specific subject of valuation even if the assessor, for whatever reason, does not have a sufficiently large battery of input data for the valuation of this subject. 
Furthermore, the requirement of data relevance is placed on the battery of input data in the form of their biggest possible similarity in all pricing factors with the subject of valuation. By creating a standardized unit of thought, this shortcoming which can also be encountered in valuation practice can also be eliminated very effectively. By re-applying the correction coefficients, the entire set of valuation items can be valued using a standardized unit without the need to search for another battery of input data.

\section{Conclusion}

The aim of this paper was to present a modified version of specific valuation methods which can be used if a sufficiently large battery of input data is not available in order to determine the market price of the subject of valuation. The modification of the comparative valuation method was performed using a standardized model property playing the role of means for a double application of the selected correction coefficients. This procedure should take into account all parameters of an inhomogeneous set of valuation items even if there is no sufficient battery of input data for each item of this inhomogeneous set. The aim of the contribution was thus met. A modified version of the comparative valuation method was applied to value the model property. The total market price of the model real estate resulted at 39,805,274 CZK based on the application of the modified valuation methods.

Future research could look at the possibilities of modifying the yield valuation methods which could lead to their unification as it was the case of the comparative valuation method in this paper. This would be appreciated mainly by the assessors as they often encounter a lack of input data for determining the market prices of the valuation subject and not only in the field of real estate valuation.

The limitations of this modification are found in the impossibility of applying a standardized thought unit to the valuation of any type of real estate. When applying this modified method, it is therefore always necessary to create a standardized unit of thought for each type of real estate separately.

\section{Literature:}

1. Abidoye, R. B., Chan, A. P. C.: Improving property valuation accuracy: a comparison of hedonic pricing model and artificial neural network. Pacific Rim Property Research Journal. 2018, 24(1), 71-83 p. ISSN 1444-5921.

2. Abidoye, R. R., Junge, M., Lam, T. Y. M., Oyedokun, T. B., Tipping, M. L.: Property valuation methods in practice: evidence from Australia. Propetry Management. 2019, 37(5), 701-718 p. ISSN 0263-7472.

3. Alexandridis, A. K., Karlis, D., Papastamos, D., Andritsos, D.: Real Estate valuation and forecasting in non-homogeneous markets: A case study in Greece during the financial crisis. Journal of the Operational Research Society. 2019, 70(10), 1769-1783 p. ISSN 0160-5682.

4. Baranano, A., De La Pena, J. I., Moreno, R.: Valuation of real-estate losses via Monte Carlo simulation. Economic Research-Ekonomska Istrazivanja. 2020, 33(1), 1867-1888 p. ISSN 1331-677X.

5. Bellman, L., Lind, H., Öhman, P.: How does education from a high-status university affect professional property appraisers' valuation judgments? Journal of Real Estate Practice and Education. 2016, 19(2), 99-124 p. ISSN 1521-4842.

6. Czech Republic, Decree No. 441 from 17. December 2013, on the implementation of the law on property valuation. In: Legal Code of the Czech Republic. 2013, Part 173, 7422-7611. ISSN 1211-1244.

7. Evans, T. A.: An estimate of the accuracy of hedonic real estate valuations using the orange county bankruptcy. Economica. 2012, 79(316), 703-720 p. ISSN 0013-0427.

8. Ferreira, F. A. F., Spahr, R. W., Sunderman, M. A.: Using multiple criteria decision analysis (MCDA) to assist in estimating residential housing values. International Journal of
Strategic Property Management. 2016, 20(4), 354-370 p. ISSN 1648-715X.

9. Gabrielli, L., French, N. (2020): Pricing to market: property valuation methods - a practical review. Journal of property Investment and Finance. 2020, ISSN 1463-578X.

10. Gdakowicz, A., Putek-Szelag, E.: The use of statistical methods for determining attribute weights and the influence of attributes on property value. Real Estate Management and Valuation. 2020, 28(4), 33-47 p. ISSN 2300-5289.

11. Hromada, E.: Decision-support tools and assessment methods. Sustainable Building and Refurbishment for Next Generetions. 2013, 669-672 p.

12. Hromada, E.: Real estate valuation using data mining software. 5th Creative Construction Conference (CCC 2016). 2016, 284-291 p.

13. Jilemnicka, L., Berka, V., Hromada, E.: Development of Real Estate Market in the Czech Republic. Acta Polytechnica. 2008, 48(5), 9-13 p.

14. Krulický, T., Horák, J.: Real estate as an investment asset. SHS Web of Conferences: Innovative Economic Symposium 2018 - Milestones and Trends of World Economy (IES2018). 2019.

15. Krulický, T., Vrbka, J., Brabenec, T.: A relationship between the value of the whole and separate parts. IOP Conference Series: Materials Science and Engineering. 2020.

16. Kucharska-Stasiak, E., Olbińska, K.: Reflecting sustainability in property valuation-defining the problem. Real Estate Management and Valuation. 2018, 26(2), 60-70 p. ISSN 2300-5289.

17. Kucharska-Stasiak, E.: Reproduction of real estate valuation methodology in practice. An attempt at identifying sources of divergences. Real Estate Management and Valuation. 2014, 22(2), 67-79 p. ISSN 2300-5289.

18. Kutasi, D., Badics, M. C.: Valuation methods for the housing market: evidence from Budapest. Acta Oeconomica. 2016, 66(3), 527-546 p. ISSN 0001-6373.

19. Meszek, W.: Property valuation under uncertainty. Simulation vs strategic model. International Journal of Strategic Property Management. 2013, 17(1), 79-92 p. ISSN 1648-715X. 20. Small, G., Vail, M., Akbar, D.: Property values and regional economic vitality: valuation methods as an indicator of property market behaviour. Australian Journal of Regional Studies. 2016, 22(2), 285-306. ISSN 1030-7923.

21. Tajani, F., Morano, P., Ntalianis, K.: Automated valuation models for real estate portfolios: a method for the value updates of the property assets. Journal of Property Investment and Finance. 2018, 36(4), 324-347 p. ISSN 1463-578X.

22. Tajani, F., Morano, P., Salvo, F., De Ruggiero, M.: Property valuation: the market approach optimised by a weighted appraisal model. Journal of Property Investment and Finance. 2019, 38(5), 399-418 p. ISSN 1463-578X.

23. Vrbka, J., Junga, P., Krulický T. (2019): Methodology for Determining the Rate of Return on Rental of Built-up Land. Ad Alta-Journal of Interdisciplinary Research, 9(2), 364-370. ISSN 1804-7890.

24. Vrbka, J., Krulický, T., Brabenec, T., Hejda, J.: Determining the increase in a building's appreciation rate due to a reconstruction. Sustainability. 2020, 12(18). ISSN 2071-1050.

Primary Paper Section: A

Secondary Paper Section: AH, AE 